\title{
Surgically Created Structure
}

National Cancer Institute

\section{Source}

National Cancer Institute. Surgically Created Structure. NCI Thesaurus. Code C25761.

Any anatomical feature created by surgery. This includes structures created to mimic the function of a structure removed by surgery or destroyed by disease. 